\title{
Employment Persistence
}

Charles A. Fleischman and Joshua Gallin ${ }^{1}$

June 5, 2001

1. Division of Research and Statistics, Federal Reserve Board, Washington, DC 20551. Email: cfleischman@frb.gov and jgallin@frb.gov. Phone 2024526473 (Fleischman, contact) and 2024522877 (Gallin). We would like to thank Bill Wascher and Bruce Fallick for helpful comments. The views expressed in this paper are not necessarily those of the Federal Reserve System or its employees. 


\begin{abstract}
The recent U.S. expansion has provided employment opportunities that otherwise would not have been available to individuals at the bottom end of the skill distribution. Will these opportunities bestow lasting benefits, in terms of greater future employability, or will those who benefitted most from the tight labor market also lose the most when labor demand softens? To answer this question, we construct synthetic cohorts from the Current Population Survey in order to identify persistence in cohort-level employment rates in excess of persistence in aggregate macroeconomic conditions. We argue that this approach should be superior to tests for hysteresis in the aggregate unemployment rate. Our method allows us to abstract away from changes in the composition of the labor force by focusing on particular demographic groups. In addition, we control for some important unobserved influences, such as a possible decline in the quality of a high school education, that mainly vary across cohorts. After controlling for aggregate conditions, we find little evidence of significant persistence in cohorts' employment rates; the effects of aggregate shocks are essentially dissipated within three years. However, we also find that the average lifetime employment rate of cohorts of lesseducated men is significantly associated with the economic conditions that prevailed when the cohorts first entered the labor market. At a more disaggregated level, we find that employment of younger workers shows a larger and more persistent response to aggregate shocks than does employment of older workers; employment of less-educated workers shows a greater effect on impact, but a bit less persistence, than does employment of more-educated workers; and employment of non-whites shows a more persistent response than does employment of whites.
\end{abstract}




\section{Section I: Introduction and Literature Review}

Late last year, after more than 10 years of economic expansion, the U.S. unemployment rate had fallen to its lowest level since 1970, and the labor force participation rate and the employment-to-population ratio hit record levels. The high level of aggregate labor demand has provided opportunities to workers that otherwise would not have been available: jobs for the non-employed, full-time work for parttimers, and faster promotions for all. Indeed, as shown in Table 1, groups with lower employment rates in 1994 have seen the biggest gains in employment since then: The employment-to-population ratios for black men increased from 56.1 percent in 1994 to 60.8 percent in 2000, compared with an increase from 63.5 percent to 65.1 percent for white men; similarly, the employment-to-population ratios of those with a high school diploma or less rose from 52.9 percent in 1994 to 55.2 percent in 2000, while the rate for college graduates actually fell slightly from 79.1 percent to 78.2 percent. $^{1}$

\begin{tabular}{|c|c|c|}
\hline \multicolumn{3}{|c|}{$\begin{array}{l}\text { Table } 1 \\
\text { Employment-to-Population Ratio by Demographics } \\
\end{array}$} \\
\hline & 1994 & 2000 \\
\hline Total & 62.5 & 64.5 \\
\hline \multicolumn{3}{|l|}{ Race } \\
\hline White & 63.5 & 65.1 \\
\hline Black & 56.1 & 60.8 \\
\hline \multicolumn{3}{|l|}{ Education $^{1}$} \\
\hline College or More & 79.1 & 78.2 \\
\hline High School or Less & 52.9 & 55.2 \\
\hline
\end{tabular}

1. Data prior to 1994 are not comparable because of the redesign of the Current Population Survey (CPS). See Polivka and Miller (1998) for estimates of the effects of the CPS redesign on measures of employment and unemployment for different demographic groups. 
In this paper, we ask whether these new opportunities to gain job-related skills have bestowed permanent benefits on their recipients in terms of the future employability. Or, come next recession, will those who benefitted most from the tight labor market fall first and farthest, essentially reaping no long-term rewards from the recent current conditions? These questions motivate much of the research on whether cyclical variation in labor demand can have persistent or permanent effects on the functioning of the labor market. The presence or absence of hysteresis-commonly defined as path dependence in the unemployment rate arising from permanent effects on the natural rate of unemployment of transitory cyclical fluctuations in labor demand-has important implications for the conduct of monetary policy. If, for example, the recent low rates of unemployment have caused the natural rate to decline, there may be less inflationary pressure building in the economy_particularly in the labor market; on the other hand, if the natural rate has remained roughly constant—and inflation has been held in check by more temporary factors - then cost pressures are likely building.

The literature does not provide compelling evidence of hysteresis in the U.S. labor market. Roberts and Morin's (1999) summary of the existing macroeconomics literature shows that most studies have focused primarily on testing for a unit root in the aggregate unemployment rate, the presence of which is interpreted as evidence of hysteresis. ${ }^{2}$ There is no consensus on whether there is a unit root in the U.S. unemployment rate, with some specifications rejecting a unit root (Mitchell, 1993; Song and $\mathrm{Wu}, 1997)$ and others failing to reject (Nelson and Plosser, 1982). Roberts and Morin's own test for hysteresis, which they conducted in the context of a price-price Phillips curve, turned up no evidence of what they call "permanent" hysteresis. However, they did find some indications that past levels of the unemployment rate have a transitory effect on the current level of the NAIRU.

In contrast to this aggregate time-series approach, micro-labor economists have mainly focused their analysis of hysteresis on the relationship between the exit rate from

2. Roberts and Morin (1999) and Jaeger and Parkinson (1994) have argued that the presence of a unit root in the unemployment rate is a necessary but not sufficient condition for hysteresis. Exogenous changes in labor market institutions (e.g. the statutory minimum wage) could generate a unit root in the unemployment rate even if past labor market performance does not affect the current steady state. 
unemployment (a fundamental determinant of the natural rate) and the duration of an unemployment spell using individual-level panel data sets. Beginning with Heckman and Borjas (1980), labor economists have asked whether unemployment begets further unemployment. If the probability of exiting unemployment declines as the length of the spell increases - there is negative duration dependence - then hysteresis is possible because changes in the distribution of unemployment spells by duration could affect the natural rate. Wilkinson (1997) finds some evidence of negative duration dependence in spells of unemployment in Canada consistent with hysteresis, though the effect is quite small, and Arulampalam, Booth, and Taylor (2000) find evidence for hysteresis-like effects-what they call scarring - in an individual-level panel of British labor force participants. Heckman and Borjas (1980) found no evidence that previous occurrences of unemployment or their duration affected future labor market outcomes once they controlled for sample selection and heterogeneity bias. However, because of data limitations, the labor economics literature has not addressed the equally important question of whether employment experience raises an individual's probability of remaining employed; in that case, the flow rates out of employment (another fundamental determinant of the natural rate) would exhibit true negative duration dependence.

This paper falls in the middle ground between the micro and macro literatures. We apply time-series methods to a data set of single-birth-year cohorts of males constructed from repeated cross sections of individuals in the Current Population Survey (CPS); we use the March CPS (MCPS) for our main results and the outgoing rotations (OGR) as a robustness check. ${ }^{3}$ We follow these cohorts over time in order to estimate the effect of changes in aggregate labor demand on the cohorts' labor market experiences. We focus on each cohort's employment-to-population ratio (EPR) as our measure of labor market outcomes. For our analysis, the cohort-level EPR is a more useful measure than the unemployment rate because we are interested in tracing out how employment responds to aggregate shocks, regardless of whether it is the labor force participation rate or the unemployment rate that adjusts. Moreover we believe that the

3. We chose the MCPS because that month's survey also includes the Annual Demographic Supplement. Although we looked at some of the data from the supplement in our initial explorations, in this paper we use only the MCPS and the OGR. 
somewhat fuzzy distinction between being unemployed and out of the labor force argues for studying the EPR rather than the unemployment rate. ${ }^{4}$

We describe and estimate a simple dynamic model where an individual's employment in the current period depends on his previous employment experience, various personal characteristics, and current aggregate labor market conditions. We then estimate a cohort-level version of this model. Our goal is to identify any persistence in the cohort-level employment rates in excess of the persistence in aggregate macroeconomic conditions. The key parameter of interest is the coefficient on the lagged EPR. If this coefficient is greater than or equal to one, then transitory aggregate demand shocks have permanent effects on cohorts' EPRs.

Our approach offers some advantages over both the macro and micro literatures. With the CPS data we can control for composition effects and focus on particular subsets of the population. In this way, our cohort data offer some of the benefits of the individual-level panel data sets used in the micro-labor literature, but without the small sample-size problems associated with the commonly used panel data sets. While we cannot control for all compositional changes in the aggregate data, by following cohorts we can control for some important unobserved influences-such as a possible decline in the quality of a high school education - that mainly vary across cohorts and confound aggregate analysis.

We find that after controlling for the persistence in aggregate economic conditions, there is no evidence of significant hysteresis or persistence in the cohorts' EPRs. Specifically, our point estimates imply that the effects of an aggregate GDP gap shock-defined as deviations of actual GDP from an estimated trend-are essentially dissipated within three years. There are some minor differences in persistence across demographic groups. Specifically, GDP gap shocks have somewhat more persistent effects on the employment rates of non-whites. In addition, we found that younger workers are both more susceptible to the effects of aggregate shocks on impact and over time. On the other hand, employment rates of men with at most a high school education

4. Moreover, in the absence of strong and variable trends, the EPR would be a more appropriate cyclical control variable for the Phillips Curve-as it combines the cyclical variations in both the participation rate and the unemployment rate. 
show no more persistence in response to an aggregate shock than those with at least some college, although the total effect of an aggregate shock is much larger for the less educated workers.

In addition, we found that the labor market conditions that prevailed at the time of a less-educated cohort's entry into the labor market appear to affect the cohort's average EPR over their lifetime. Specifically, cohorts who enter the labor market when the aggregate unemployment rate is high tend to have lower average EPRs. This can be interpreted as a hysteresis-like effect, because new entrants are permanently affected by their experiences. ${ }^{5}$ Second, we found that both the more- and less-educated cohorts' lifetime average employment rates are strongly positively correlated with the share of less-educated workers in the birth-year cohort. In effect, this correlation suggests that the secular rise in educational attainment has reduced the average "quality" of both education groups, and thus their average labor market outcomes. (See Rosenbaum 2000 for more on this point.) Of course, we are hesitant to give this a truly causal interpretation because education decisions are based in part on expectations of labor market opportunities.

The rest of this paper is organized as follows. In the next section, we describe our construction of cohort level data using repeated cross sections from the MCPS and the OGR. In section III, we sketch out a model where weeks worked by an individual in the current year depends on both cumulative employment experience in prior years and current economic conditions, and we show that without any heroic assumptions we can aggregate our model up to the cohort level. In section IV we present our estimates using the cohort data. Finally, in section V, we provide a summary and conclusion.

\section{Section II: The Data}

Because of the very limited panel structure in the CPS, we cannot follow individuals over any significant period of time. ${ }^{6}$ Instead, we follow various cohorts of similar men constructed from the repeated cross-sections in the MCPS over the period

5. This finding is similar to Beaudry and DiNardo's (1991) result that individuals entering the labor market during periods of high aggregate unemployment rates have lower wages, on average, over their lifetime.

6. See Fallick and Fleischman (2001) for a description of the panel structure in the CPS. 
from 1964 to 1998, and observe how the groups' labor market performance evolves over time. We excluded women from our study because the dramatic changes in female labor force participation that occurred during our time sample make it difficult to estimate and interpret the size and persistence of shocks to women's employment rates. In addition, our sample excludes members of the military.

We defined a cohort, c, by

$$
c=y e a r-a g e+16
$$

the year members of the cohort turned age 16. We further divided each birth-year cohort into those with at least some college (highest grade attained greater than 12) and those with at most a high school degree (highest grade attained less than or equal to 12). For simplicity, we call these the college and high school cohorts. In some cases we further divided the sample into whites and non-whites.

For each cohort and year, we calculated the EPR as the fraction of cohort members reporting that they worked for pay in the second week in March, as measured in the MCPS from 1964 to 1998 . We use this measure of the EPR—which we call the current EPR, or CEPR - rather than one based on the retrospective questions asked each March as part of the Annual Demographic Supplement, which we call the REPR. Although a retrospective measure, such as the number of weeks worked in the previous calendar year, is closest in definition to what we would want, this series has several problems. First, there is an apparent break in 1976 caused by the introduction of new questions for collecting weeks worked data. ${ }^{7}$ In addition, it is likely that the CEPR suffers from less measurement error; it is easier to remember if you worked last week than to remember how many weeks you worked last year. Over time, the two measures of the EPR tell roughly the same story: Within cohorts, the average correlation between the CEPR and the REPR is .88 for the less-educated cohorts and .76 for more-educated cohorts.

7. Prior to the March 1976 survey, the retrospective weeks-worked data were reported only on a bracketed basis. We imputed continuous values for the pre-1976 data by using the means from the same weeks-bracket in the later years. See Juhn (1992). 
We limited our sample to men aged 20 to 55 for those with at most a high school diploma and to men aged 25 to 55 for those with at least some college. We chose these age ranges because we wanted the initial age to reflect a cohort's permanent entry into the labor market and the terminal age to precede most workers' retirements.

Chart 1 shows the full range of observations available. We limited the sample by requiring that each cohort have at least 12 observations. Because the college cohorts enter the labor market four years later than the high-school cohorts, the last six cohorts (1978 to 1983) are excluded from the college sample because they have fewer than 12 observations after age 25. Our panel is unbalanced, both in the sense that there are unequal numbers of observations per cohort and that there are unequal numbers of observations per calendar year. With the full high-school sample shown, we have a minimum of 12 and a maximum of 35 usable observations per cohort, a minimum of 19 and a maximum of 35 observations per calendar year, and a total of 1041 cohort-year observations; for the college sample, we have a total of 969 cohort-year observations.

To conduct some robustness checks, we used the methods described above to construct cohorts using the OGR data. The advantages of these data are that they are representative of a whole calendar year and that they have more individual observations per cohort. For instance, the average cohort in the MCPS contains about 460 individuals, while the average cohort in the OGR is about three times as large. The disadvantage of the OGR is that the data begin only in 1981, severely reducing the length of our panel. Because we are interested in estimating a dynamic model, panel length is more important than is cohort size, especially since the MCPS cohorts are already quite large. Thus we only report results from the OGR, along with those using the MCPS data, when we present separate results by race, for which we have fewer observations per cohort. 


\section{Section III: An Empirical Model}

Our cohort-level analysis is motivated by an individual-level model of employment determination. In the individual-level model, the fraction of the year that person $\mathrm{i}$, who is a member of cohort $\mathrm{c}$, works during year $\mathrm{t}, \mathrm{WW}_{\mathrm{ct}}^{\mathrm{i}}$, depends, in part, on a vector of personal characteristics, $Z_{\mathrm{ct}}^{\mathrm{i}}$, and a vector of aggregate factors, $\mathrm{X}_{\mathrm{t}}$. In addition, human capital accumulation - in the form of on-the-job training and the acquisition of basic workplace skills_-increases an individual's employability.

The data from the CPS do not allow us to estimate a structural model for the conditional probability of employment. Rather, we write down a reduced-form linearized version of the relationship, including various unobserved (or unmodeled) influences, $\mathrm{u}_{\mathrm{c}}^{\mathrm{i}}$, for the fraction of the year that a person is employed as

$$
W W_{c t}^{i}=\phi+\delta_{c} W W_{c, t-1}^{i}+\alpha_{c} Z_{c t}^{i}+\beta_{c} X_{t}+u_{c t}^{i}
$$

where we proxy for accumulated human capital that influences probability of employment as the fraction of the previous year the person was employed.

We assume that the unobserved determinants can be written as a combination of a cohort effect, $\eta_{c}$, an aggregate time effect, $v_{\mathrm{t}}$, an individual fixed effect, $\omega_{\mathrm{c}}^{\mathrm{i}}$, and an idiosyncratic error, $\varepsilon_{\mathrm{ct}}^{\mathrm{i}}$ :

$$
u_{c t}^{i}=\eta_{c}+v_{t}+\omega_{c}^{i}+\epsilon_{c t}^{i}
$$

where each component is mean zero.

Although equation (1) above is specified for individual-level data, Deaton (1985) shows that for a model such as ours that is linear in parameters, though not necessarily linear in variables, it is possible to take cohort means and rewrite (1) as a cohort-level relationship:

$$
E P R_{c t}=\delta_{c} E P R_{c, t-1}+\alpha_{c} Z_{c t}+\beta_{c} X_{t}+\eta_{c}+v_{t}+\epsilon_{c t}
$$


where the average percent of weeks worked in a year by all members of a cohort is equal to the EPR for the cohort:

$$
E P R_{c t}=\frac{1}{N_{c}} \sum_{i=1}^{N_{c}} W W_{c t}^{i}
$$

and $\mathrm{N}_{\mathrm{c}}$ is the number of individuals in the cohort.

Specifically, we estimate the following linear-in-variables dynamic relationship based on (3):

$$
E P R_{c t}=\delta_{c} E P R_{c, t-1}+\beta_{c 0} \operatorname{gap}_{t}+\beta_{c l} \operatorname{gap}_{t-1}+\alpha_{c 0} A_{c t}+\alpha_{c l} A_{c t}^{2}+\eta_{c}+\epsilon_{c t}
$$

where each cohort's EPR rate depends on the cohort's previous employment experience though a lag of the EPR; the cohort's position in a typical life-cycle profile of employment status, captured by a quadratic in age, $\mathrm{A}_{\mathrm{ct}}$; and on aggregate labor market conditions, $v_{t}$, which are measured by the contemporaneous and once lagged GDP gap-defined as the log of potential GDP minus the log of actual GDP for the first quarter of each calendar year. ${ }^{8}$

The dynamic behavior of EPR around the average age profile is governed by ${ }_{c}$, $\$_{\mathrm{c} 0}$, and $\$_{\mathrm{c} 1}$. Consider the effects of a fully transitory shock to , $\mathrm{ct}$. On impact, the cohort's employment rate increases by ${ }_{\mathrm{c}} \mathrm{c}$, and then the effect decays exponentially: In the next year, the effect is $*_{\mathrm{c}}$ times, ${ }_{\mathrm{c}}$, in the second year it is ${ }_{\mathrm{c}}{ }_{\mathrm{c}}$ times,,$_{\mathrm{ct}}$, and so on. The dynamics associated with a GDP shock are slightly more complex. Consider, for example, the effects of a fully transitory unit shock to the GDP gap. The initial effect

8. We defined the GDP gap as the difference in the logs of potential and actual GDP. We estimated potential GDP by regressing the log of actual GDP on the unemployment rate and a time trend with breaks in 1973, 1980, 1990, and 1995. The GDP gap is one of many possible aggregate controls. Two obvious alternatives are time dummies and the unemployment rate. Table 2 shows how the structure of our data set makes the use of dummy variables difficult. In an effort to maximize the length of our panel, there are many years for which we have only a handful of observations. We prefer the GDP gap to the unemployment rate because it eliminates any need to explicitly model the accounting link between the aggregate unemployment rate and the cohort-level employment rates. 
on $\mathrm{EPR}_{\mathrm{ct}}$ is simply $\$_{\mathrm{c} 0}$. In the next period, the effect of the unit GDP gap shock is $*_{\mathrm{c}} \$_{\mathrm{c} 0}+\$_{\mathrm{c} 1}$. The second-period effect then decays exponentially at a rate $\left(1-*_{\mathrm{c}}\right) \cdot{ }^{9}$

We expect that $\$_{\mathrm{c} 0}$ should be negative; that is, an increase in the GDP gap — which is a decrease in actual GDP relative to potential—should reduce a cohort's employment rate. The sign of $\$_{\mathrm{c} 1}$ is ambiguous. A positive value of $\$_{\mathrm{c} 1}$ reduces the effect of a GDP gap shock in the first period after impact and in each subsequent period.

Although $*_{\mathrm{c}}$ determines the persistence of an idiosyncratic shock, and $*_{\mathrm{c}}, \$_{\mathrm{c} 0}$, and $\$_{\mathrm{c} 1}$ determine the dynamics in response to a GDP gap shock, these parameters do not fully describe the dynamics and persistence of the cohorts' employment rates because the GDP gap itself is quite persistent. Rather, these parameters determine the persistence of the EPR in excess of the persistence of the driving shocks, which is exactly what we would like to measure in answering the question of whether transitory aggregate fluctuations can have permanent or persistent effects on cohorts' employment rates.

\section{Section IV: Estimation and Results}

We follow Deaton (1985) by interpreting the cohort-level means as error-ridden measures of the actual population means. ${ }^{10}$ In other words, we treat the cohort-level

9. In principle, the panel structure of our cohort-level data can also be exploited to perform a more powerful test for a unit root (Levin and Lin, 1992), in much the same way that Song and $\mathrm{Wu}(1997)$ use state-level data. In practice, however, our point estimates were so far from one that we did not bother with formal tests for a unit root.

10. In most respects, estimation of (6) or (7) using the panel of cohort-level observations is no different from the estimation of a true panel data model, and to this point we have not addressed any of the particular issues raised by using a panel of cohorts rather than a panel of individuals. Indeed, the key distinction between true panels of individuals and our panel of cohorts is that the cohort data are presumed to be error-ridden measures of population values while the individual level data are assumed to be true measures. To address the measurementerror issue, which is an additional source of downward bias on the coefficient on lagged EPR, Collado (1997) derives measurement error corrections for the within-group estimator (equivalent to a least squares dummy variable estimator) and for a GMM estimator. Measurement error may be a second-order concern for us because the cross sections in the MCPS and OGR are very large, especially compared to the Consumer Expenditures Survey and Great Britain's Family Expenditure Survey, the data sources for most early estimation using repeated cross sections. 
observations as "aggregate" variables that are defined for a more narrow group than is common. ${ }^{11}$ Thus, we can use the cohort data as we would any other aggregate measure to estimate reduced-form relationships. ${ }^{12}$ As a practical matter, however, we find that the estimates of equation (5) for the individual cohorts are very imprecise-and we do not report these estimates here. ${ }^{13}$

To improve the efficiency of our estimates, we form a panel by stacking equation (5) and restricting the coefficients ${ }_{c}, \$_{\mathrm{c} 1}, \$_{2},{ }_{\mathrm{c} 0}$, and " ${ }_{\mathrm{c} 1}$ to be the same across cohorts within an education class:

$$
\begin{aligned}
& E P R_{46, t}=\delta E P R_{46, t-1}+\beta_{0} \operatorname{gap}_{t}+\beta_{1} g_{a p}+\alpha_{0} A_{46, t}+\alpha_{1} A_{46, t}^{2}+\eta_{46}+\epsilon_{46, t} \\
& \text {.. } \\
& \text {.. } \\
& E P R_{83, t}=\delta E P R_{83, t-1}+\beta_{0} \text { gap }_{t}+\beta_{1} \text { gap }_{t-1}+\alpha_{0} A_{83, t}+\alpha_{1} A_{83, t}^{2}+\eta_{83}+\epsilon_{83, t}
\end{aligned}
$$

Because of important differences in the cyclicality of employment between more and less educated workers (see e.g. Keane and Prasad (1993), Hoynes (1999)), we separate each birth-year cohort into a high-school cohort (at most a high-school degree) and a college cohort (at least some college education) and estimate the relationship separately for each education class. We formed the panels by stacking high-school cohorts who turned age 16 between 1946 and 1983 or college cohorts who turned age 16 between 1942 and 1977, and the regressions cover the period from 1965 to 1998. We identify the dynamics of the cohort-level employment rate as deviations from the life-cycle profile of employment status. We allow for three sources of deviations from the life-cycle pattern: Aggregate effects, measured by the GDP gap, cohort-specific fixed effects, $0_{c}$, and an idiosyncratic error, , ct.

11. The cohort-level means likely have a lower signal-to-noise ratio than is typical in most aggregate measures because they are based on fewer observations.

12. Conceptually, this is no different from regressing the unemployment rate of a particular demographic group on aggregate conditions (e.g. Wachter (1976)) or regressing industry- (or state-) level employment on aggregate employment (e.g. Blanchard and Katz (1992)).

13. Results are available from the authors upon request. 
Table 2a

Estimates of Persistence in the Cohort-Level Employment-to-Population Ratio (High School or less: 1965-1998)

\begin{tabular}{|c|c|c|c|c|c|c|c|}
\hline \multirow{2}{*}{\multicolumn{2}{|c|}{ Lagged Emp. Rate }} & \multicolumn{2}{|c|}{ LSDV } & \multicolumn{2}{|c|}{ Anderson-Hsiao } & \multicolumn{2}{|c|}{ GMM } \\
\hline & & .265 & .321 & .323 & .351 & .286 & .317 \\
\hline & & $(.024)$ & $(.028)$ & $(.066)$ & $(.090)$ & $(.070)$ & $(.101)$ \\
\hline \multicolumn{2}{|c|}{ GDP Gap } & -.511 & -.603 & -.626 & -.629 & -.640 & -.644 \\
\hline & & $(.032)$ & $(.032)$ & $(.042)$ & $(.043)$ & $(.042)$ & $(.043)$ \\
\hline \multirow{2}{*}{\multicolumn{2}{|c|}{ Lagged GDP Gap }} & --- & .135 & --- & .063 & --- & .047 \\
\hline & & & $(.035)$ & & $(.071)$ & & $(.075)$ \\
\hline \multicolumn{2}{|l|}{ RMSE } & .021 & .021 & .030 & .030 & .029 & .029 \\
\hline \multicolumn{2}{|c|}{ Observations } & 925 & 925 & 887 & 887 & 849 & 849 \\
\hline \multirow{5}{*}{ Effect at } & & \multicolumn{6}{|c|}{ Percent of Shock Remaining } \\
\hline & Impact & 100 & 100 & 100 & 100 & 100 & 100 \\
\hline & Impact +1 & 27 & 10 & 32 & 25 & 29 & 24 \\
\hline & Impact +2 & 7 & 3 & 10 & 9 & 8 & 8 \\
\hline & Impact +3 & 2 & 1 & 3 & 3 & 2 & 3 \\
\hline
\end{tabular}

Note: Figures in parentheses are standard errors. All models include cohort effects. The age-profile coefficient estimates are not shown, but are available from the authors. Percent of shock remaining at impact $+\mathrm{n}$ refers to the percentage of the initial response of the cohorts' employment rate to a shock to the GDP gap remaining $n$ years after impact.

\section{High-school cohorts}

Chart 2 plots the deviations of the EPR from the estimated age-employment-rate profiles for selected cohorts with a high school degree or less, which we refer to as high-school cohorts. Each panel shows the deviation of a cohort's measured employment 
rate in year $t$ from the typical age profile of the employment rate. ${ }^{14}$ This chart gives a visual impression of the covariation between aggregate conditions and cohorts' EPRs that we use to identify our model. The chart shows that, after controlling for the life cycle, cohorts' EPRs are strongly procyclical; that is they covary negatively with the GDP gap. What is unclear is how persistent is the EPR once the effects of the GDP gap and the secular decline in the mean cohort EPR are removed as well. ${ }^{15}$

Table 2a shows estimates of (6) for the high-school cohorts. The upper panel contains the actual estimates. We used these estimates to calculate the percent of a fully transitory unit shock to the GDP gap that remains after one, two, and three years; these impulse responses are shown in the lower panel.

The first column of Table $2 \mathrm{a}$ shows our model estimates using a least squares dummy variable (LSDV) approach. It indicates that a one percentage point increase in the GDP gap lowers a cohort's employment rate by 0.5 percentage point on impact. Alternatively, a one standard deviation sized shock to the GDP gap (about 3.2 percentage points) lowers a high school cohort's employment rate by 1.6 percentage points. After one year, about $1 / 4$ of this effect remains $(\delta=.27)$, and it is essentially gone after three years. In column 2, we add the lagged GDP gap, which enters with a positive and statistically significant coefficient, effectively dissipating most of the effect of a GDP gap shock in two years. What little remains decays exponentially at a rate of about 70 percent a year Based on the point estimates in column 2, each cohort's employment rate is only 0.06 percentage point lower in the year after the shock, and only 0.02 percentage point lower two years after the shock-which represents only about 3 percent of the initial impact. ${ }^{16}$

14. We estimate the typical age profile of the EPR using the regression reported in the first column of table 2a below, which includes the lagged EPR, the contemporaneous GDP gap, age, age squared, and cohort dummies.

15. The average EPR decreases with successive cohorts, and these differences in the mean EPR are picked up by the cohort dummies included in the regression; later, we will show that the trend in the mean EPR across cohorts matches up well with the decline in the percentage of each complete birth-year cohort that has no more than a high school education.

16. These results are not sensitive to the inclusion of a proxy for the military buildup during the Vietnam War. 
However, it has been widely noted (see Hsiao, 1986) that LSDV estimation of a dynamic panel data model with fixed effects yields downward-biased estimates of the effect of lagged dependent variables in a finite sample because some of the persistence in the response to a shock is going to be mis-characterized as part of the estimated fixed effect. ${ }^{17}$ In our cohort-level estimation we face the same problem: The coefficient on lagged EPR is identified from the persistence of deviations of the EPR from its insample mean (after controlling for the age profile and aggregate conditions), but, in a finite sample, any persistent deviation from the true cohort mean will be mischaracterized as part of the estimated fixed effect, thus reducing the apparent persistence picked up by lagged EPR.

Anderson and Hsiao (1981, 1982) propose an instrumental variables estimator that can overcome this problem in true panel data. Specifically, AH suggest eliminating the fixed cohort effects by differencing (6):

$$
\begin{aligned}
& \Delta E P R_{46, t}=\delta \Delta E P R_{46, t-1}+\beta_{0} \Delta g a p_{t}+\beta_{1} \Delta \operatorname{gap}_{t-1}+\alpha_{0}+2 * \alpha_{1} A_{46, t}+\Delta \epsilon_{46, t} \\
& \text {.. } \\
& \text {.. } \\
& \Delta E P R_{83, t}=\delta \Delta E P R_{83, t-1}+\beta_{0} \Delta g a p_{t}+\ddot{\beta}_{1} \Delta \operatorname{gap}_{t-1}+\alpha_{0}+2 * \alpha_{1} A_{83, t}+\Delta \epsilon_{83, t}
\end{aligned}
$$

In (7), the residual, $\Delta \varepsilon_{c t}$, is correlated with the $\Delta E P R_{c t-1}$. Anderson and Hsiao (1981, 1982) suggest using as instruments either the twice lagged level, $E P R_{c t-2}$, or the twice lagged difference, $\Delta E P R_{c t-2}$. However, Arellano and Bond (1991) and Kiviet (1995) among others have noted that using the twice-lagged difference usually results in less precise estimates, which is the case for our results as well. We also note that if $\epsilon_{c t}$ is a white-noise residual, then $\Delta \varepsilon_{c t}$ is $\operatorname{MA}(1)$.

We present estimates using Anderson-Hsiao (AH) with the twice-lagged level as an instrument in columns 3 and 4 of table 2, and the standard errors for these estimates are robust to the $\mathrm{MA}(1)$ structure of $\Delta \varepsilon_{c t}$. As shown in column 3, the coefficient on lagged EPR is a bit larger than the coefficient on lagged EPR in

17. Judson and Owen (1997) show that the bias in the LSDV estimates can be quite severe even with as many as 30 observations per cross-section unit. 
column 1. More important, column 4 shows that the coefficient on lagged GDP gap is smaller than that in column 2, and it is statistically insignificant. Without the coefficient on lagged GDP gap, the AH estimates show more excess persistence than implied by the LSDV estimates-especially in the first two years after impact.

We report GMM estimates of (7) in columns 5 and 6. Our GMM estimator is a generalization of the $\mathrm{AH}$ estimator, in that it uses the twice- and thrice-lagged levels of EPR as instruments and uses a more optimally weighted covariance matrix. The estimates in columns 5 and 6 are very similar to those presented for the AH estimator.

\begin{tabular}{|c|c|c|c|c|c|c|c|}
\hline & stimates of & $\begin{array}{l}\text { ersisten } \\
\text { More tl }\end{array}$ & $\begin{array}{r}\text { Tabl } \\
\text { in the } \\
\text { High } S \\
\end{array}$ & $\begin{array}{l}\text { b } \\
\text { hort-Le } \\
\text { ool: } 196 \\
\end{array}$ & $\begin{array}{l}\text { Emplo } \\
\text { 1998) }\end{array}$ & nent Ra & \\
\hline & & & & Ander & -Hsiao & & \\
\hline Lagged & & .338 & .351 & .470 & .475 & .335 & .333 \\
\hline & & $(.035)$ & $(.036)$ & $(.073)$ & $(.076)$ & $(.068)$ & $(.071)$ \\
\hline GDP Gal & & -.164 & -.191 & -.200 & -.201 & -.209 & -.209 \\
\hline & & $(.018)$ & $(.024)$ & $(.033)$ & $(.033)$ & $(.031)$ & $(.031)$ \\
\hline Lagged & DP Gap & & .046 & & .023 & & -.003 \\
\hline & & & $(.024)$ & & $(.035)$ & & $(.032)$ \\
\hline RMSE & & .016 & .016 & .025 & .025 & .023 & .023 \\
\hline Observat & ons & 840 & 840 & 825 & 825 & 809 & 809 \\
\hline & & & & ent of Sl & k Rema & & \\
\hline Effect at & Impact & 100 & 100 & 100 & 100 & 100 & 100 \\
\hline & Impact +1 & 34 & 11 & 47 & 36 & 34 & 35 \\
\hline & Impact +2 & 11 & 4 & 22 & 17 & 11 & 12 \\
\hline & Impact +3 & 4 & 1 & 10 & 8 & 4 & 4 \\
\hline $\begin{array}{l}\text { Note: Figur } \\
\text { coefficient } \\
\text { impact }+\mathrm{n} \mathrm{r} \\
\text { to the GDP }\end{array}$ & $\begin{array}{l}\text { in parenthese } \\
\text { mates are not } \\
\text { rs to the perc } \\
\text { remaining n }\end{array}$ & $\begin{array}{l}\text { ge of th } \\
\text { rs after }\end{array}$ & $\begin{array}{l}\text { rrors. Al } \\
\text { available } \\
\text { itial resp } \\
\text { act. }\end{array}$ & $\begin{array}{l}\text { odels incl } \\
m \text { the aut } \\
\text { of the cc }\end{array}$ & $\begin{array}{l}\text { e cohort e } \\
\text { rs. Percen } \\
\text { rts' empla }\end{array}$ & $\begin{array}{l}\text { ts. The } \\
\text { f shock r } \\
\text { lent rate }\end{array}$ & $\begin{array}{l}\text {-profile } \\
\text { ining at } \\
\text { shock }\end{array}$ \\
\hline
\end{tabular}




\section{College cohorts}

Chart 3 plots the deviations of the EPR from the estimated age profiles for selected cohorts with more than a high school education-we call these the college cohorts. This chart shows visually that the covariance between EPR for college cohorts and the GDP gap is less pronounced, and this is apparent in the coefficient estimates reported in table $2 \mathrm{~b}$ - which, as with table $2 \mathrm{a}$ shows the coefficient estimates in the top panel and the impulse responses to a GDP gap shock in the bottom panel. As shown in the third row of the table, a contemporaneous GDP gap shock has little effect on the EPR, with a one percentage point increase in the GDP gap lowering a college cohort's EPR by about 0.2 percentage points. Alternatively, a one standard deviation increase in the GDP gap (3.2 percentage points) results in a 0.6 percentage point decrease in a college cohort's employment rate. This result accords well with the common observation that more educated workers are better insulated from economic shocks. Although the impact effect of GDP shock is only about 1/3 as large for the college cohorts as for the high school cohorts, we find that effects of the shocks are somewhat more persistent for the college cohorts. The first row of the table shows that our estimate of $\delta$ for the college cohorts range from 0.33 to 0.47 , compared with a range of 0.27 to 0.35 for the high school cohorts.

Although we find it interesting that a college cohort's response to a GDP shock is slightly more persistent than a high school cohort's response, we think that the small initial response of the college cohort makes studying the subsequent dynamics less interesting - at least at this level of aggregation. We therefore prefer to focus the remainder of our attention in this paper to the employment dynamics of the high school cohorts. 
Table 3

A-H Estimates of Persistence in the Cohort-Level Employment Rate: Age Effects (High School Sample: 1966-1998)

\begin{tabular}{|c|c|c|c|c|c|}
\hline & & \multicolumn{2}{|c|}{ Model A } & \multicolumn{2}{|c|}{ Model B } \\
\hline \multirow{2}{*}{\multicolumn{2}{|c|}{ Lagged EPR }} & \multicolumn{2}{|c|}{.409} & \multicolumn{2}{|c|}{.352} \\
\hline & & \multicolumn{2}{|c|}{$(.069)$} & \multicolumn{2}{|c|}{$(.071)$} \\
\hline \multirow{2}{*}{\multicolumn{2}{|c|}{ Lagged EPR X Age }} & \multicolumn{2}{|c|}{-.014} & \multicolumn{2}{|c|}{-.005} \\
\hline & & \multicolumn{2}{|c|}{$(.007)$} & \multicolumn{2}{|c|}{$(.008)$} \\
\hline \multirow{2}{*}{\multicolumn{2}{|c|}{ GDP Gap }} & \multicolumn{2}{|c|}{-.662} & \multicolumn{2}{|c|}{-.938} \\
\hline & & \multicolumn{2}{|c|}{$(.040)$} & \multicolumn{2}{|c|}{$(.095)$} \\
\hline \multirow{2}{*}{\multicolumn{2}{|c|}{ GDP Gap X Age }} & & & \multicolumn{2}{|c|}{.019} \\
\hline & & & & \multicolumn{2}{|c|}{$(.005)$} \\
\hline RMSE & & \multicolumn{2}{|c|}{.030} & \multicolumn{2}{|c|}{.029} \\
\hline Observati & & \multicolumn{2}{|c|}{887} & \multicolumn{2}{|c|}{887} \\
\hline \multicolumn{6}{|c|}{$\begin{array}{l}\text { Effect of } 1 \text { Percentage Point GDP Gap Shock on Cohort Employment Rate } \\
\text { (Percent of Shock Remaining) }\end{array}$} \\
\hline \multirow{6}{*}{ Effect at } & & \multicolumn{2}{|c|}{ Model A } & \multicolumn{2}{|c|}{ Model B } \\
\hline & & Age $=19$ & Age $=39$ & Age $=19$ & Age $=39$ \\
\hline & Impact & $\begin{array}{c}0.662 \\
(100.0)\end{array}$ & $\begin{array}{c}0.662 \\
(100.0)\end{array}$ & $\begin{array}{c}0.938 \\
(100.0)\end{array}$ & $\begin{array}{c}0.558 \\
(100.0)\end{array}$ \\
\hline & Impact +1 & $\begin{array}{l}0.271 \\
(40.9)\end{array}$ & $\begin{array}{l}0.085 \\
(12.9)\end{array}$ & $\begin{array}{l}0.330 \\
(35.2)\end{array}$ & $\begin{array}{l}0.141 \\
(25.2)\end{array}$ \\
\hline & Impact +2 & $\begin{array}{l}0.111 \\
(16.7)\end{array}$ & $\begin{array}{c}0.011 \\
(1.7)\end{array}$ & $\begin{array}{l}0.116 \\
(12.4)\end{array}$ & $\begin{array}{c}0.035 \\
(6.4)\end{array}$ \\
\hline & Impact +3 & $\begin{array}{c}0.045 \\
(6.8)\end{array}$ & $\begin{array}{c}0.001 \\
(0.2)\end{array}$ & $\begin{array}{c}0.041 \\
(4.4)\end{array}$ & $\begin{array}{c}0.009 \\
(1.6)\end{array}$ \\
\hline
\end{tabular}

Note: Figures in parentheses are standard errors. Regressions of the change in EPR on a constant, age, and the variables indicated in the top panel. Instruments are the twice-lagged level of EPR, the twice-lagged EPR interacted with age, the GDP gap, the GDP gap interacted with age (column 2 only), age, and a constant. Percent of shock remaining at impact $+\mathrm{n}$ refers to the percentage of the initial response of the cohorts' employment rate to a shock to the GDP gap remaining $n$ years after impact. 
Employment persistence by age

In Table 3 we investigate the possibility that the degree of persistence of the EPR for high school cohorts varies by age. The table contains estimates of two specifications, both of which include the interaction of the lagged EPR and age, where age is normalized to zero for 19-year-olds. In the first column of the top panel of the table, the interaction of age and the lagged EPR is negative and statistically significant, indicating that older workers' EPRs exhibit less persistence in response to a GDP gap shock or an idiosyncratic cohort-specific shock. The bottom panel shows the size of the effect of a one percentage point shock to the GDP gap on the EPR of less-educated men at age 19 and age 39, and the percent of the initial shock still remaining in parentheses. Based on the estimates reported in the first column of the upper panel, younger men exhibit some persistence-41 percent of the initial impact remains after one year and 17 percent remains after two years; in contrast, a 39-year-old experiences almost no persistence at all-only 2 percent of the initial effect remains after two years.

In column 2 of the top panel, we allow both the initial impact of the GDP gap shock and its persistence to vary with age by interacting the age and the GDP gap term. Not surprisingly, we find that the EPRs of older workers respond less to changes in labor market conditions; for instance, the initial effect of a GDP gap shock is only about three-fifths as large for a 39 -year-old $\left(-.938+[39-19]^{*} .019=.558\right)$ as it is for a 19-year-old (-.938). However, after allowing the impact effect to differ, the coefficient on the lagged EPR-age interaction is statistically insignificant (although still negative), thus there is little evidence suggesting that the EPRs of younger cohorts show any more persistence in response to aggregate labor demand shocks. 
Table 4

Estimates of Persistence in the Cohort-Level Employment Rate

by Race

(Anderson-Hsiao)

\begin{tabular}{|c|c|c|c|c|c|c|c|}
\hline & & \multicolumn{2}{|c|}{ All } & \multicolumn{2}{|c|}{ White } & \multicolumn{2}{|c|}{ Non-White } \\
\hline & & MCPS & OGR & MCPS & OGR & MCPS & OGR \\
\hline \multirow{2}{*}{\multicolumn{2}{|c|}{ Lagged EPR }} & .346 & .252 & .269 & .188 & .351 & .336 \\
\hline & & $(.075)$ & $(.067)$ & $(.080)$ & $(.066)$ & $(.074)$ & $(.078)$ \\
\hline \multirow{2}{*}{\multicolumn{2}{|c|}{ GDP Gap }} & -.996 & -.869 & -.997 & -.881 & -1.118 & -.885 \\
\hline & & $(.130)$ & $(.078)$ & $(.151)$ & $(.082)$ & $(.367)$ & $(.256)$ \\
\hline \multirow{2}{*}{\multicolumn{2}{|c|}{ GDP Gap X Age }} & .023 & .014 & .022 & .014 & .033 & .017 \\
\hline & & $(.007)$ & $(.004)$ & $(.007)$ & $(.004)$ & $(.019)$ & $(.013)$ \\
\hline \multicolumn{2}{|l|}{ RMSE } & .032 & .016 & .031 & .017 & .100 & .056 \\
\hline \multicolumn{2}{|c|}{ Observations } & 540 & 540 & 540 & 540 & 540 & 540 \\
\hline & & \multicolumn{6}{|c|}{ Percent of Shock Remaining } \\
\hline \multirow[t]{4}{*}{ Effect at } & Impact & 100 & 100 & 100 & 100 & 100 & 100 \\
\hline & Impact +1 & 35 & 25 & 27 & 19 & 35 & 34 \\
\hline & Impact +2 & 12 & 6 & 7 & 4 & 12 & 11 \\
\hline & Impact +3 & 4 & 2 & 2 & 1 & 4 & 4 \\
\hline
\end{tabular}

Note: Figures in parentheses are standard errors. Regressions of the change in EPR on a constant, age, and the variables indicated in the top panel. Instruments are the twice-lagged level of EPR, the GDP gap, age, GDP gap interacted with age, and a constant. We used the first-quarter GDP gap in the MCPS regressions and the annual average of the GDP gap for the OGR regressions. Percent of shock remaining at impact $+\mathrm{n}$ refers to the percentage of the initial response of the cohorts' employment rate to a shock to the GDP gap remaining $n$ years after impact.

\section{Employment persistence by race}

In table 4 we present estimates of (7) separately for white and non-white members of high-school cohorts. We expect that GDP gap shocks will have a greater initial effect on non-whites because aggregate data show that the unemployment rate 
for non-whites is more sensitive to changes in aggregate labor market conditions. As we mentioned above, our cohort observations are error-ridden measures of population means. Although we believe that measurement error is not a large problem for our main results using complete cohorts, measurement error may be important for our estimates of the employment rates of the non-white cohorts, which have only about one-tenth of the observations of a complete cohort. Thus, unlike above, we present our results using both the data from the MCPS and the OGR. Recall that the OGR data provide us with more observations per cohort and also provide annual averages as opposed to one reading in March. However, the OGR sample is only about half the length of the MCPS sample.

Table 4 presents results using the Anderson-Hsiao method for the shorter OGR sample (1980-1998) for the full cohorts, and separately for whites and nonwhites. In all cases, the MSE is considerably smaller in the OGR data than in the MCPS. ${ }^{18}$ The first two columns of the table show that, for the full sample, the results using the MCPS and the OGR are essentially the same. The results using the MCPS data suggest that the response to shocks does not differ by race in an economically significant way. However, the results using the OGR, shown in columns four and six, indicate that the effects of a GDP gap shock are more persistent for non-whites than for whites even though the initial effect of a shock is about the same for the two groups. ${ }^{19}$ The percent of the shocks that remains after one, two, and three years is shown in the lower panel. Based on the results in the fourth column using the OGR sample, more than 80 percent of the initial impact on the EPRs of less-educated white men dissipates within a year, and the effects are almost entirely gone within three years. For non-whites, the shocks have more persistent effects, but even so, are more than 95 percent gone by the end of three years.

18. One should note that the estimated impact effect of a shock to the GDP gap is considerably larger when the sample is restricted to the 1980s and 1990s.

19. One might have expected that the estimated coefficient on the lagged EPR would be larger when estimated using the OGR instead of the MCPS because cohort-level measure error is presumably less with the OGR. However, as we mentioned above, the OGR covers a shorter time period, making it more difficult to identify a dynamic model. 


\section{Modeling the cohort fixed effects}

We have so far assumed that there are cohort fixed effects, and we have either run regressions using the first differences of cohorts' EPR or run the regressions in levels including cohort dummies. To further test the sensitivity of our results to our choice of estimation technique, we also attempted to model the determinants of the cohort fixed effects directly, thereby eliminating the potential problems associated with dynamic models with fixed effects. We argue that the cohort fixed effects are capturing both the lifetime sensitivity of each cohort's EPR to labor market conditions upon entry into the labor market and the secular decline in the "quality" of both the high-school and college cohorts over time, as well as other factors.

We use the aggregate unemployment rate upon entry into the labor market to measure initial conditions. Initial conditions may affect a cohort's EPR in much the same way that any previous labor market experience could: A strong labor market upon entry may offer opportunities to build human capital that a weaker market does not. In fact, one might believe that such an effect might be largest during the formative stages of one's career. ${ }^{20}$

To measure the average "quality" or skill of a particular cohort of high school educated men, we calculated the fraction of the total age cohort accounted for by people with a high school degree or less. Our goal is to control for the trend toward greater education during the period we study. Over this period, the share of each cohort who attended at least some college increased sharply, and it has been argued elsewhere (see Rosenbaum 2000) that the resulting change in the composition of the high-school and college cohorts implies that the average quality of the individual in each educational group has likely gone down. ${ }^{21}$ Thus, we posit that a high school cohort that accounts for a large fraction of the total cohort is, on average, more skilled than a high

20. Beaudry and DiNardo (1991) found that a worker's wage depends in part on the aggregate conditions that prevailed when the worker entered the labor market.

21. Rosenbaum (2000) and others have shown that the secular decline in the cohorts' share of high-school graduates can reduce the average quality of both the high school and college cohorts if those workers now receiving at least some college education were above average in the high school cohort but are below average in the college cohort. 
school cohort that accounts for a small fraction of the total cohort, and will therefore have higher EPRs. ${ }^{22}$

Chart 4 plots the estimated cohort dummies for high-school cohorts from the regressions in column 1 of the table $2 \mathrm{a}$, along with the aggregate unemployment rate for each cohort during the year the cohort turned 18 and the percentage of the cohort members with at most a high school degree for cohorts 1946 to $1982 .{ }^{23}$ Although there is a clear relationship between the cohort dummies and the education percentile in both charts, the relationship between the cohort dummies and the initial unemployment rate is less clear. Table 5, which presents results from a regression of the cohort dummies on the cohort characteristics, shows that the characteristics affect the high school dummies in the expected way: A low initial unemployment rate has a negative effect, and the education percentile has a positive effect. Together, the cohort characteristics explain over 85 percent of the variation of the cohort dummies, suggesting that they are useful way to parameterize the cohort effects.

Table 6 presents estimates of a model with our direct measures of the cohort effects for the high school educated sample, both total and separately by race. The RMSE for the model in column 1 is little different from those in Table 2a, indicating that there is essentially no loss in fit. As we expected, the coefficients on the lagged employment rate are larger than in the associated specification with cohort dummies, and the implied dynamics are therefore more persistent. ${ }^{24}$ Nevertheless, the conclusion that the EPR exhibits little persistence in response to an aggregate shock in excess of that due to the persistence of the shock itself remains intact when estimated on the full sample. The racial breakdown indicates that although the initial effects of a shock are only slightly larger for non-whites than for whites, the effects are much more persistent.

22. Conversely, a college cohort that accounts for a small fraction of the total cohort should be more skilled than a college cohort that accounts for a large fraction of the total cohort, and will therefore have a higher EPR.

23. Recall that cohorts are defined by the year its members turned 16 .

24. However, when we regressed the residuals from these models on a full set of cohort dummies, the dummies were jointly significant, suggesting that the estimates of the coefficient on the lagged EPR in Table 6 are biased up because some of the estimated persistence is really a mis-classification of the cohort effect. 
Three years after a GDP gap shock, nearly 10 percent of the original effect remains for non-whites.

\begin{tabular}{|c|c|}
\hline \multicolumn{2}{|c|}{$\begin{array}{c}\text { Table } 5 \\
\text { Explaining The Cohort Dummies } \\
\text { (High School Sample) } \\
\end{array}$} \\
\hline \multirow[t]{2}{*}{ Education Percentile } & -.178 \\
\hline & $(.070)$ \\
\hline \multirow[t]{2}{*}{ Initial Unemployment } & .838 \\
\hline & $(.070)$ \\
\hline $\mathrm{R}^{2}$ & .87 \\
\hline RMSE & .377 \\
\hline Observations & 37 \\
\hline \multicolumn{2}{|c|}{$\begin{array}{l}\text { Note: Figures in parentheses are standard errors. All } \\
\text { variables are scaled by their standard errors. Data are for } \\
\text { cohorts whose members turned } 16 \text { between } 1946 \text { and } \\
1982 \text {. }\end{array}$} \\
\hline
\end{tabular}

In any event, the coefficient on the education percentile and the initial unemployment rate are perhaps of more interest. The regression coefficients are consistent with our priors: A greater share of individuals with no more than a high school degree is associated with a higher cohort employment rate for the less educated workers over the life cycle. Moreover, a higher unemployment rate upon a cohort's entry into the labor market is associated with a lower life-time employment rate. This effect is consistent with a scarring story, where workers with limited employment experience early in life suffer permanently lower employment rates over their life time. This is itself a kind of persistence, and deserves further study. 
Table 6

Estimates of Persistence in the Cohort-Level

Employment Rate:

Parameterized Fixed Cohort Effects (Without Cohort

Dummies)

(1966-1998)

\begin{tabular}{|c|c|c|c|c|}
\hline & All & White & $\begin{array}{l}\text { Non- } \\
\text { White }\end{array}$ \\
\hline \multirow{2}{*}{\multicolumn{2}{|c|}{ Lagged EPR }} & .561 & .480 & .394 \\
\hline & & $(.027)$ & $(.028)$ & $(.030)$ \\
\hline \multirow{2}{*}{\multicolumn{2}{|c|}{ GDP Gap }} & -.636 & -.623 & -.734 \\
\hline & & $(.035)$ & $(.034)$ & $(.104)$ \\
\hline \multirow{2}{*}{\multicolumn{2}{|c|}{ Lagged GDP Gap }} & .251 & .230 & -.131 \\
\hline & & $(.037)$ & $(.037)$ & $(.106)$ \\
\hline \multirow{2}{*}{\multicolumn{2}{|c|}{ Education Percentile }} & -.139 & -.142 & .285 \\
\hline & & $(.012)$ & $(.012)$ & $(.029)$ \\
\hline \multirow{2}{*}{\multicolumn{2}{|c|}{ Initial Unemployment }} & -.318 & -.302 & -.708 \\
\hline & & $(.051)$ & $(.050)$ & $(.148)$ \\
\hline \multicolumn{2}{|l|}{ RMSE } & .023 & .022 & .066 \\
\hline \multicolumn{2}{|c|}{ Observations } & 925 & 925 & 925 \\
\hline \multirow{5}{*}{ Effect at } & & \multicolumn{3}{|c|}{ Percent of Shock Remaining } \\
\hline & Impact & 100 & 100 & 100 \\
\hline & Impact +1 & 16.7 & 11.1 & 57.2 \\
\hline & Impact +2 & 9.3 & 5.3 & 22.6 \\
\hline & Impact +3 & 5.2 & 2.6 & 8.9 \\
\hline
\end{tabular}

Note: Figures in parentheses are standard errors. Percent of shock remaining at impact $+\mathrm{n}$ refers to the percentage of the initial response of the cohorts' employment rate to a shock to the GDP gap remaining $n$ years after impact. 


\section{V: Summary and Conclusions}

As of late last year, the recent economic boom had driven the unemployment rate to a 30-year low, providing opportunities to workers that otherwise would not have been available. An obvious question presents itself: Will workers benefit permanently from having had these opportunities? Our search for persistence-in its extreme form, hysteresis - centers on the time series properties of the employment-to-population ratio (EPR) for single-year age cohorts. We constructed the cohorts from many years of March CPS (MCPS) data, thereby turning a simple time series of cross sections into a panel of cohorts, and then estimated a simple dynamic model of the EPR with both aggregate and cohort-level controls. As such, our approach differs from both macro studies, which focus on the aggregate unemployment rate, and micro studies, which focus on the rate of exit from unemployment. Indeed, our approach combines some of the advantages of the two approaches because we can control for composition and focus on particular subsets of the population without facing sample-size problems as severe as those in studies that use individual-level data.

We controlled for aggregate effects in all our specifications using the GDP gap. Thus our approach can be interpreted as a search for "excess persistence", that is, persistence in the EPR in excess of persistence in the aggregate shock. Regardless of our model specification or estimation technique, our results suggest that there is little excess persistence at the cohort level. Almost all the effects of a GDP gap shock dissipate after three years. This holds for various demographic groups, although we did find some evidence for more persistence for young or non-white cohorts.

Our results are consistent with a related strand of research on displaced workers. This literature, which focuses on workers whose job loss results from economic restructuring, has shown that the average displaced worker suffers a large and persistent earnings loss. It is sometimes assumed that these losses are associated with unemployment, an assumption that dovetails well with our search for employment persistence. However, Jacobson, LaLonde, and Sullivan (1993) show that almost all displaced workers find stable employment within a year and a half of losing their jobs, and that most of the earnings loss is a function of lower wages at these new jobs. In 
other words, even permanent shocks - from the perspective of the worker-do not have a permanent effect on workers' employment. ${ }^{25}$ Rather, the effect is felt in wages.

Although we found little in the way of excess persistence, we did find intriguing evidence that a cohort's entire EPR profile is affected by the economic conditions that prevailed at the time its members entered the labor market. In particular, we found that for less-educated people a high unemployment rate upon entry into the labor market is associated with less employment throughout the cohort's "life." This could occur if a strong labor market upon entry offers opportunities to build human capital that a weaker market does not, and is consistent with Beaudry and DiNardo's (1991) finding that workers' wages depend in part on the aggregate conditions that prevailed upon entry.

25. Of course, we recognize that, unlike individuals with more marginal labor force attachment, many displaced workers are older and relatively high-skilled who have suffered as a result of a clearly identifiable exogenous shock. 


\section{References}

Anderson, T. W. , and Cheng Hsiao. (1981). "Estimation of Dynamic Models with Error Components." Journal of the American Statistical Association. 76: 598606.

Anderson, T. W. , and Cheng Hsiao. (1982). "Formulation and Estimation of Dynamic Models Using Panel Data.” Journal of Econometrics 18:47-82.

Arellano, Manuel and Stephen Bond. (1991) "Some Tests of Specification for Panel Data: Monte Carlo Evidence and an Application to Employment Equations." Review of Economic Studies. 58: 277-297.

Arulampalam, Wiji, Alison Booth, and Mark P. Taylor. (2000) "Unemployment Persistence." Oxford Economic Papers 52:24-50

Beaudry, Paul and John DiNardo. (1991) “The Effect of Implicit Contracts on the Movement of Wages over the Business Cycle: Evidence from Micro Data" Journal of Political Economy. 99: 665-688.

Blanchard, Olivier J. and Lawrence F. Katz. (1992) "Regional Evolutions.” Brookings Papers on Economic Activity. 1992:1 pp. 1-61.

Blanchard, Olivier, and Lawrence Summers, (1986) "Hysteresis and the European Unemployment Problem." In Fischer, Stanley, ed., NBER Macro-economics Annual. Vol. 1, Cambridge: Massachusetts Institute of Technology Press, 1986, pp. 1578.

Breitung, J. (1994) "Some Simple Tests of the Moving Average Hypothesis." Journal of Time Series Analysis, 1531

Collado, M. Dolores. (1997) "Estimating Dynamic Models from Time Series of Independent Cross-Sections.” Journal of Econometrics 82:37-62.

Deaton, Angus. (1985) "Panel Data from Time Series of Cross-Sections." Journal of Econometrics 30:109-126.

Fallick, Bruce C. and Charles A. Fleischman. (2001) "The Missing Gross Flow: Employer-to-Employer Changes." Finance and Economics Discussion Series , Federal Reserve Board. (Forthcoming)

Hall, Robert, (1979) "A Theory of the Natural Rate of Unemployment and the Duration of Unemployment," Journal of Monetary Economics, 5, 153-69. 
Heckman, James and George Borjas. (1980) "Does Unemployment Cause Future Unemployment? Definitions, Questions, and Answers from a Continuous Time Model of Heterogeneity and State Dependence." Economica 47:247-284.

Hoynes, Hilary. (1999) “The Employment, Earnings, and Income of Less Skilled Workers over the Business Cycle." NBER Working Paper 7188.

Hsiao, Cheng. (1986). Analysis of Panel Data. Cambridge University Press.

Jacobson, Louis, Robert LaLonde, and Daniel Sullivan. (1993) The Costs of Worker Dislocation. Kalamazoo, Mich.: W. E. Upjohn Institute for Employment Research.

Jaeger, Albert and Martin Parkinson. (1994) "Some Evidence on Hysteresis in Unemployment Rates." European Economic Review. 38: 329-342.

Judson, Ruth A. and Ann L. Owen (1997). "Estimating Dynamic Panel Data Models: A practical Guide for Macroeconomists." Finance and Economics Discussion Series, Federal Reserve Board. 1997-3

Juhn, Chinhui. (1992) "Decline of Male Labor Force Participation: The Role of Declining Market Opportunities.” Quarterly Journal of Economics. 107: 79121.

Keane, Michael and Eswar Prasad. (1993) "Skill Levels and the Cyclical Variability of Employment, Hours, and Wages.” IMF Staff Papers. 40: 711-743.

Kiviet, Jan F. (1995) "On Bias, Inconsistency, and Efficiency of Various Estimators in Dynamic Panel Data Models.” Journal of Econometrics. 68: 53-78.

Levin, Andrew and Chein-Fu Lin. (1993) "Unit Root Tests in Panel Data: Asymptotic and Finite-Sample Properties." University of California, San Diego Department of Economics Working Paper: 92-23.

Mitchell, W.F. (1993) "Testing for Unit Roots and Persistence in OECD Unemployment Rates.” Applied Econometrics., 25:1489-1501.

Nelson, C. R. and C. I. Plosser. (1982) "Trends and Random Walks in MarcoEconomic Time Series: Some Evidence and Implications." Journal of Monetary Economics. 10:139-162.

Polivka, Anne E. and Stephen M. Miller. (1998) "The CPS after the Redesign: Refocusing the Economic Lens" in Labor Statistics Measurement Issues, Haltiwanger, John, Marilyn E. Manser, and Robert Topel, eds. Chicago: The University of Chicago Press. Pp. 249-286. 
Roberts, John M. and Norman J. Morin (1999) “Is Hysteresis Important for U.S. Unemployment?" Finance and Economics Discussion Series , Federal Reserve Board. 1999-56.

Rosenbaum, Dan T. (2000) “Ability, Educational Ranks, and Labor Market Trends: The Effects of Shifts in the Skill Composition of Educational Groups." Department of Economics, University of North Carolina at Greensboro, mimeo.

Song, F. and Y. Wu. (1997) "Hysteresis in Unemployment: Evidence from 48 U.S. States." Economic Inquiry 35:235-243

Wachter, Michael L. (1976) “The Changing Cyclical Responsiveness of Wage Inflation.” Brookings Papers on Economic Activity. 1976:1 pp. 115-159.

Wilkinson, Gordon. (1997) "A Micro Approach to the Issue of Hysteresis in Unemployment: Evidence from the 1988-1990 Labour Market Activity Survey." Bank of Canada Working Paper, 97-12. 


\section{Chart 1}

\section{Unbalanced Panel Dataset--Cohort Age by Calendar Year}

\section{Calendar Year}

$\begin{array}{lllllllllllllllllllllllllllllllllllllll}\text { Cohort } & 64 & 65 & 66 & 67 & 68 & 69 & 70 & 71 & 72 & 73 & 74 & 75 & 76 & 77 & 78 & 79 & 80 & 81 & 82 & 83 & 84 & 85 & 86 & 87 & 88 & 89 & 90 & 91 & 92 & 93 & 94 & 95 & 96 & 97 & 98\end{array}$

$\begin{array}{lllllllllllllllllll}1942 & 38 & 39 & 40 & 41 & 42 & 43 & 44 & 45 & 46 & 47 & 48 & 49 & 50 & 51 & 52 & 53 & 54 & 55\end{array}$

$\begin{array}{llllllllllllllllllll}1943 & 37 & 38 & 39 & 40 & 41 & 42 & 43 & 44 & 45 & 46 & 47 & 48 & 49 & 50 & 51 & 52 & 53 & 54 & 55\end{array}$

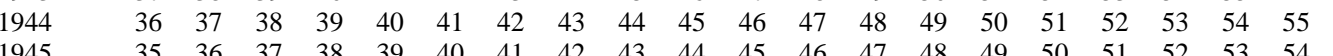

$\begin{array}{llllllllllllllllllllllll}1945 & 35 & 36 & 37 & 38 & 39 & 40 & 41 & 42 & 43 & 44 & 45 & 46 & 47 & 48 & 49 & 50 & 51 & 52 & 53 & 54 & 55 & \\ 1946 & 34 & 35 & 36 & 37 & 38 & 39 & 40 & 41 & 42 & 43 & 44 & 45 & 46 & 47 & 48 & 49 & 50 & 51 & 52 & 53 & 54 & 55\end{array}$

$\begin{array}{lllllllllllllllllllllllll}1947 & 33 & 34 & 35 & 36 & 37 & 38 & 39 & 40 & 41 & 42 & 43 & 44 & 45 & 46 & 47 & 48 & 49 & 50 & 51 & 52 & 53 & 54 & 55\end{array}$

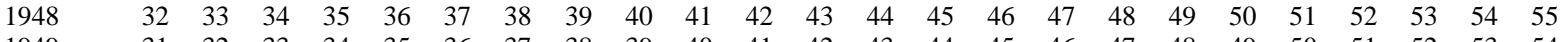

$1949 \quad \begin{array}{lllllllllllllllllllllllllllllll} & 31 & 32 & 33 & 34 & 35 & 36 & 37 & 38 & 39 & 40 & 41 & 42 & 43 & 44 & 45 & 46 & 47 & 48 & 49 & 50 & 51 & 52 & 53 & 54 & 55 & & \end{array}$

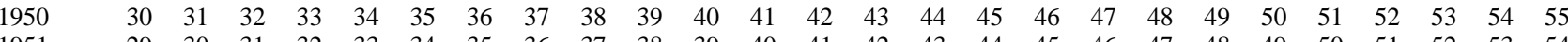

$\begin{array}{llllllllllllllllllllllllllllll}1951 & 29 & 30 & 31 & 32 & 33 & 34 & 35 & 36 & 37 & 38 & 39 & 40 & 41 & 42 & 43 & 44 & 45 & 46 & 47 & 48 & 49 & 50 & 51 & 52 & 53 & 54 & 55\end{array}$

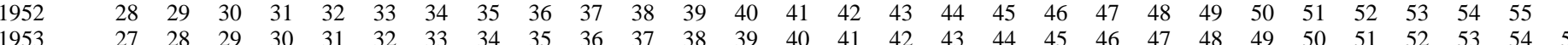

$\begin{array}{llllllllllllllllllllllllllllllllllllll}1953 & 27 & 28 & 29 & 30 & 31 & 32 & 33 & 34 & 35 & 36 & 37 & 38 & 39 & 40 & 41 & 42 & 43 & 44 & 45 & 46 & 47 & 48 & 49 & 50 & 51 & 52 & 53 & 54 & 55 & \\ 1954 & 26 & 27 & 28 & 29 & 30 & 31 & 32 & 33 & 34 & 35 & 36 & 37 & 38 & 39 & 40 & 41 & 42 & 43 & 44 & 45 & 46 & 47 & 48 & 49 & 50 & 51 & 52 & 53 & 54 & 55 & & \end{array}$

$\begin{array}{llllllllllllllllllllllllllllllllllllllll}1955 & 25 & 26 & 27 & 28 & 29 & 30 & 31 & 32 & 33 & 34 & 35 & 36 & 37 & 38 & 39 & 40 & 41 & 42 & 43 & 44 & 45 & 46 & 47 & 48 & 49 & 50 & 51 & 52 & 53 & 54 & 55\end{array}$

$\begin{array}{lllllllllllllllllllllllllllllllllllllllllll}1956 & 24 & 25 & 26 & 27 & 28 & 29 & 30 & 31 & 32 & 33 & 34 & 35 & 36 & 37 & 38 & 39 & 40 & 41 & 42 & 43 & 44 & 45 & 46 & 47 & 48 & 49 & 50 & 51 & 52 & 53 & 54 & 55 \\ 195 & 23 & 24 & 25 & 26 & 27 & 28 & 29 & 30 & 31 & 32 & 33 & 34 & 35 & 36 & 37 & 38 & 39 & 40 & 4 & 42 & 43 & 44 & 45 & 46 & 47 & 48 & 49 & 50 & 51 & 52 & 53 & 54\end{array}$

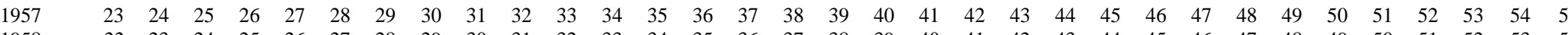

$\begin{array}{lllllllllllllllllllllllllllllllllllllllllll}1958 & 22 & 23 & 24 & 25 & 26 & 27 & 28 & 29 & 30 & 31 & 32 & 33 & 34 & 35 & 36 & 37 & 38 & 39 & 40 & 41 & 42 & 43 & 44 & 45 & 46 & 47 & 48 & 49 & 50 & 51 & 52 & 53 & 54 & 55\end{array}$

$\begin{array}{llllllllllllllllllllllllllllllllllllllllllllllllllllll}1959 & 21 & 22 & 23 & 24 & 25 & 26 & 27 & 28 & 29 & 30 & 31 & 32 & 33 & 34 & 35 & 36 & 37 & 38 & 39 & 40 & 41 & 42 & 43 & 44 & 45 & 46 & 47 & 48 & 49 & 50 & 51 & 52 & 53 & 54 & 55\end{array}$ $\begin{array}{llllllllllllllllllllllllllllllllllllllllllllllllllll}1960 & 20 & 21 & 22 & 23 & 24 & 25 & 26 & 27 & 28 & 29 & 30 & 31 & 32 & 33 & 34 & 35 & 36 & 37 & 38 & 39 & 40 & 41 & 42 & 43 & 44 & 45 & 46 & 47 & 48 & 49 & 50 & 51 & 52 & 53 & 54\end{array}$

1961

1962

1963

1964

1966

1967

1968

1969

1970

1972

1973

1974

1975

1977

1978

1979

1980

1982

1983 $\begin{array}{llllllllllllllllllllllllllllllllllllllllll}21 & 22 & 23 & 24 & 25 & 26 & 27 & 28 & 29 & 30 & 31 & 32 & 33 & 34 & 35 & 36 & 37 & 38 & 39 & 40 & 41 & 42 & 43 & 44 & 45 & 46 & 47 & 48 & 49 & 50 & 51 & 52 & 53 & 54 \\ 20 & 21 & 22 & 23 & 24 & 25 & 26 & 27 & 28 & 29 & 30 & 31 & 32 & 33 & 34 & 35 & 36 & 37 & 38 & 39 & 40 & 41 & 42 & 43 & 44 & 45 & 46 & 47 & 48 & 49 & 50 & 51 & 52 & 53\end{array}$ $\begin{array}{lllllllllllllllllllllllllllllllllllllllllllllll}20 & 21 & 22 & 23 & 24 & 25 & 26 & 27 & 28 & 29 & 30 & 31 & 32 & 33 & 34 & 35 & 36 & 37 & 38 & 39 & 40 & 41 & 42 & 43 & 44 & 45 & 46 & 47 & 48 & 49 & 50 & 51 & 52\end{array}$ $\begin{array}{llllllllllllllllllllllllllllllllllll}20 & 21 & 22 & 23 & 24 & 25 & 26 & 27 & 28 & 29 & 30 & 31 & 32 & 33 & 34 & 35 & 36 & 37 & 38 & 39 & 40 & 41 & 42 & 43 & 44 & 45 & 46 & 47 & 48 & 49 & 50 & 51\end{array}$ $\begin{array}{lllllllllllllllllllllllllllllllllllll}20 & 21 & 22 & 23 & 24 & 25 & 26 & 27 & 28 & 29 & 30 & 31 & 32 & 33 & 34 & 35 & 36 & 37 & 38 & 39 & 40 & 41 & 42 & 43 & 44 & 45 & 46 & 47 & 48 & 49 & 50\end{array}$ $\begin{array}{lllllllllllllllllllllllllllllll}20 & 21 & 22 & 23 & 24 & 25 & 26 & 27 & 28 & 29 & 30 & 31 & 32 & 33 & 34 & 35 & 36 & 37 & 38 & 39 & 40 & 41 & 42 & 43 & 44 & 45 & 46 & 47 & 48 & 49 \\ \end{array}$ $\begin{array}{lllllllllllllllllllllllllllll}20 & 21 & 22 & 23 & 24 & 25 & 26 & 27 & 28 & 29 & 30 & 31 & 32 & 33 & 34 & 35 & 36 & 37 & 38 & 39 & 40 & 41 & 42 & 43 & 44 & 45 & 46 & 47 & 48\end{array}$ $\begin{array}{llllllllllllllllllllllllllllllllll}20 & 21 & 22 & 23 & 24 & 25 & 26 & 27 & 28 & 29 & 30 & 31 & 32 & 33 & 34 & 35 & 36 & 37 & 38 & 39 & 40 & 41 & 42 & 43 & 44 & 45 & 46 & 47\end{array}$ $\begin{array}{lllllllllllllllllllllllllllll}20 & 21 & 22 & 23 & 24 & 25 & 26 & 27 & 28 & 29 & 30 & 31 & 32 & 33 & 34 & 35 & 36 & 37 & 38 & 39 & 40 & 41 & 42 & 43 & 44 & 45 & 46\end{array}$ $\begin{array}{llllllllllllllllllllllllllllll}20 & 21 & 22 & 23 & 24 & 25 & 26 & 27 & 28 & 29 & 30 & 31 & 32 & 33 & 34 & 35 & 36 & 37 & 38 & 39 & 40 & 41 & 42 & 43 & 44 & 45\end{array}$ $\begin{array}{llllllllllllllllllllllllllll}20 & 21 & 22 & 23 & 24 & 25 & 26 & 27 & 28 & 29 & 30 & 31 & 32 & 33 & 34 & 35 & 36 & 37 & 38 & 39 & 40 & 41 & 42 & 43 & 44\end{array}$ $\begin{array}{llllllllllllllllllllllll}20 & 21 & 22 & 23 & 24 & 25 & 26 & 27 & 28 & 29 & 30 & 31 & 32 & 33 & 34 & 35 & 36 & 37 & 38 & 39 & 40 & 41 & 42 & 43\end{array}$ $\begin{array}{lllllllllllllllllllllll}20 & 21 & 22 & 23 & 24 & 25 & 26 & 27 & 28 & 29 & 30 & 31 & 32 & 33 & 34 & 35 & 36 & 37 & 38 & 39 & 40 & 41 & 42\end{array}$ $\begin{array}{llllllllllllllllllllll}20 & 21 & 22 & 23 & 24 & 25 & 26 & 27 & 28 & 29 & 30 & 31 & 32 & 33 & 34 & 35 & 36 & 37 & 38 & 39 & 40 & 41\end{array}$ $\begin{array}{lllllllllllllllllllll}20 & 21 & 22 & 23 & 24 & 25 & 26 & 27 & 28 & 29 & 30 & 31 & 32 & 33 & 34 & 35 & 36 & 37 & 38 & 39 & 40\end{array}$ $\begin{array}{llllllllllllllllllll}20 & 21 & 22 & 23 & 24 & 25 & 26 & 27 & 28 & 29 & 30 & 31 & 32 & 33 & 34 & 35 & 36 & 37 & 38 & 39\end{array}$ $\begin{array}{lllllllllllllllllll}20 & 21 & 22 & 23 & 24 & 25 & 26 & 27 & 28 & 29 & 30 & 31 & 32 & 33 & 34 & 35 & 36 & 37 & 38\end{array}$ $\begin{array}{llllllllllllllllll}20 & 21 & 22 & 23 & 24 & 25 & 26 & 27 & 28 & 29 & 30 & 31 & 32 & 33 & 34 & 35 & 36 & 37\end{array}$ $\begin{array}{lllllllllllllllll}20 & 21 & 22 & 23 & 24 & 25 & 26 & 27 & 28 & 29 & 30 & 31 & 32 & 33 & 34 & 35 & 36\end{array}$ $\begin{array}{llllllllllllllll}20 & 21 & 22 & 23 & 24 & 25 & 26 & 27 & 28 & 29 & 30 & 31 & 32 & 33 & 34 & 35\end{array}$ $\begin{array}{lllllllllllllll}20 & 21 & 22 & 23 & 24 & 25 & 26 & 27 & 28 & 29 & 30 & 31 & 32 & 33 & 34\end{array}$ $\begin{array}{llllllllllllll}20 & 21 & 22 & 23 & 24 & 25 & 26 & 27 & 28 & 29 & 30 & 31 & 32 & 33\end{array}$ $\begin{array}{lllllllllllll}20 & 21 & 22 & 23 & 24 & 25 & 26 & 27 & 28 & 29 & 30 & 31 & 32\end{array}$ 
Chart 2

Employment Rates by Age--High School Cohorts
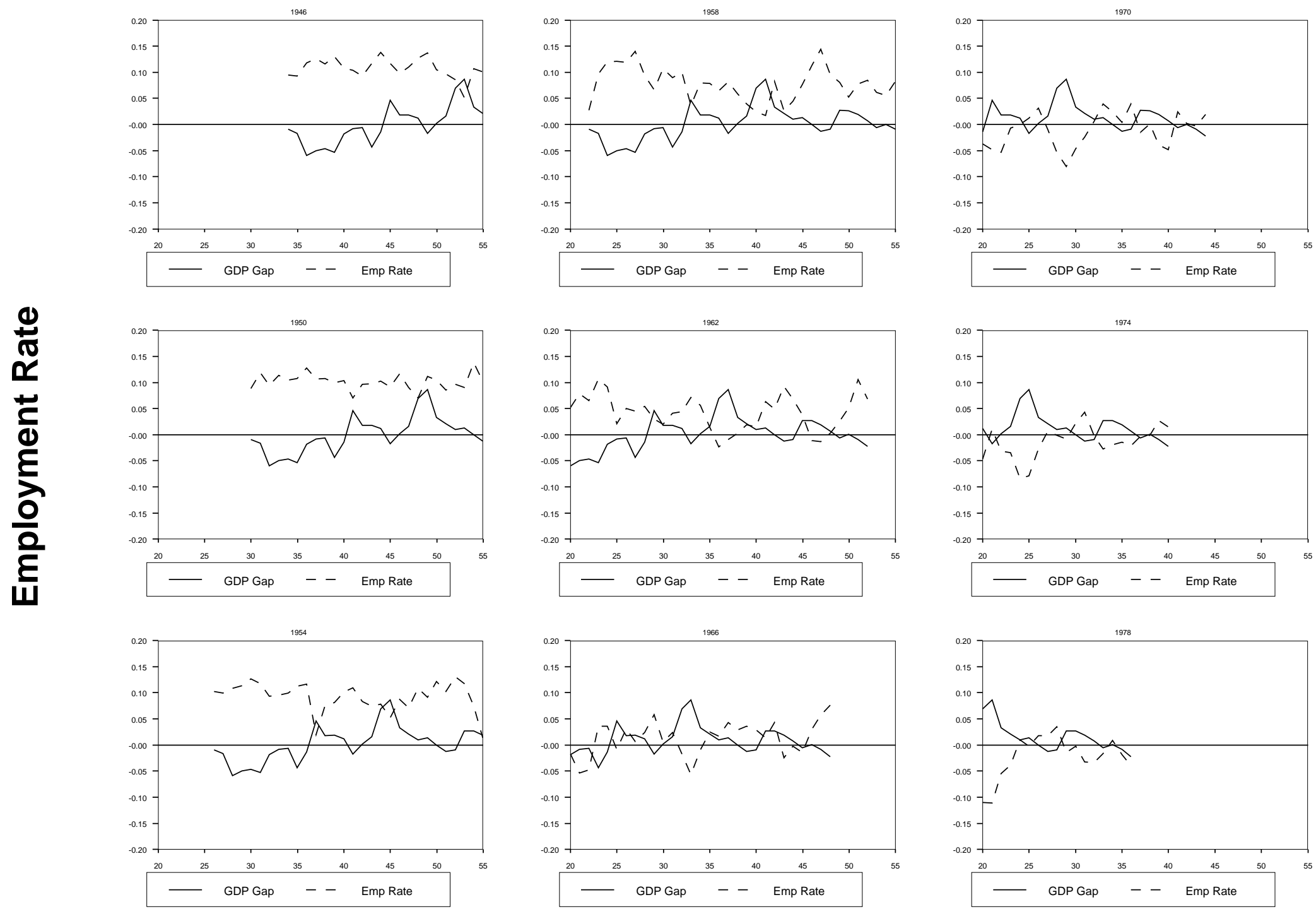

Age 
Chart 3

Employment Rates by Age--College Cohorts
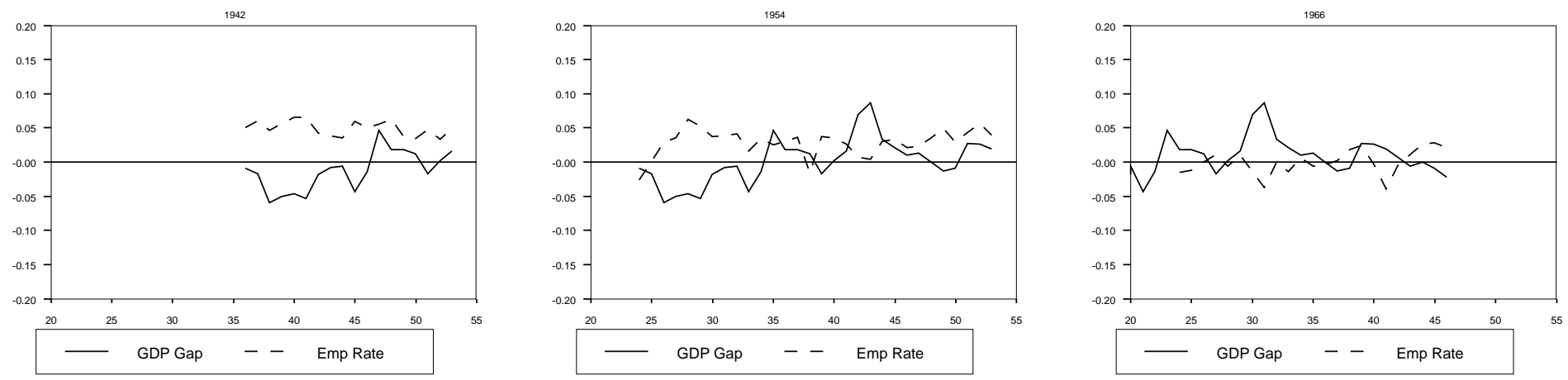

্ֻ
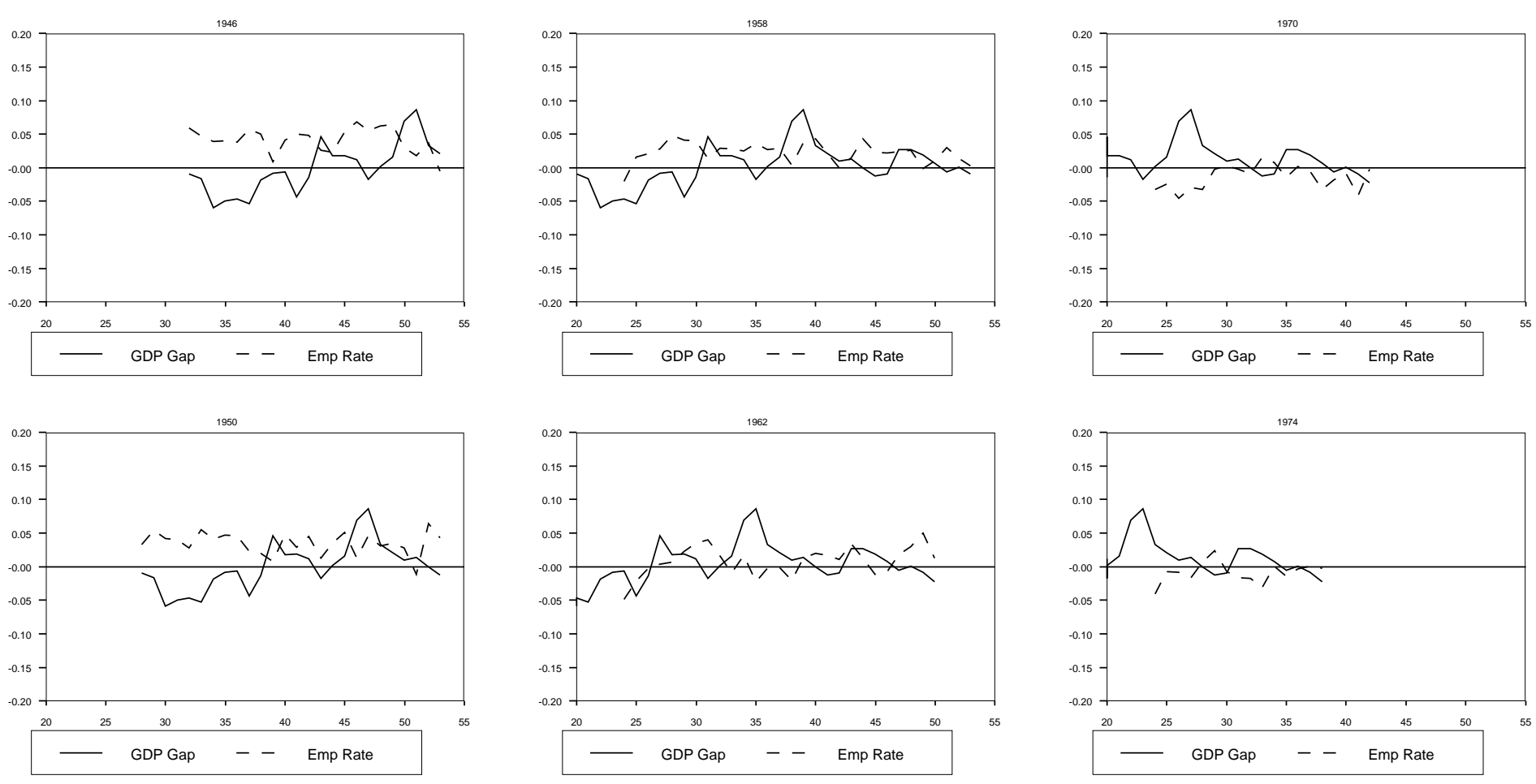

Age 
Chart 4

\section{Explaining the High School Cohort Dummies}

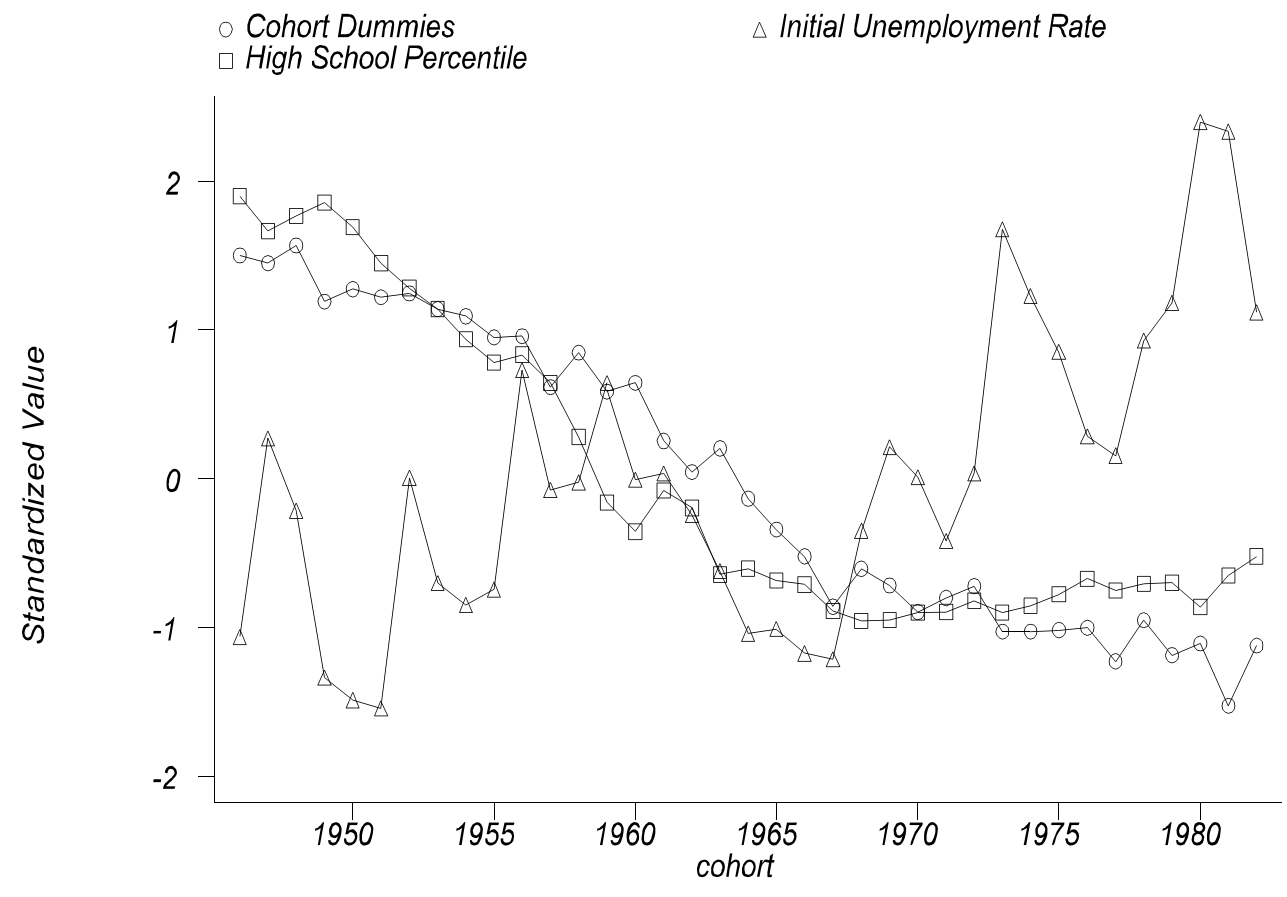

